\title{
GAO reports on CFS funding controversy
}

A new US government report on funding for chronic fatigue syndrome (CFS)-related research calls for an increase in collaboration between the two agencies responsiblefor studying the condition, but concludes that federal research on CFS is essentially on track. The report, prepared by the Government Accounting Office (GAO), was well received by the Centers for Disease

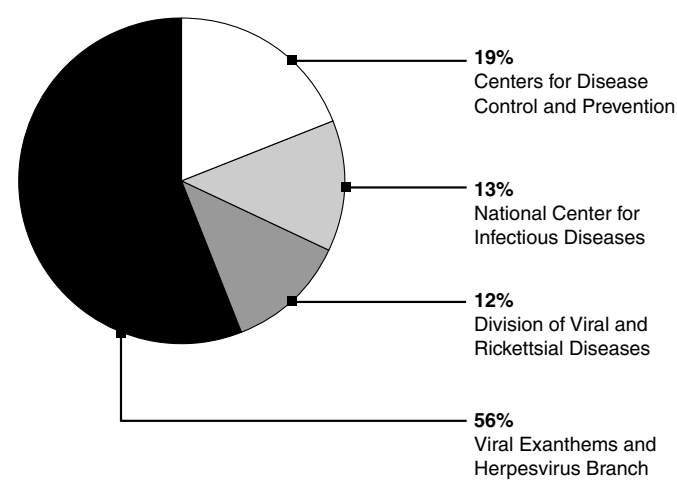

Proportion of CFS funds retained at each level of CDC, FY98-99
Control and Prevention (CDC) and the National Institutes of Health $(\mathrm{NIH})$, but has been criticized by some CFS patient activists.

The current developments are part of a chain of events that began in 1998, when William Reeves, director of the CDC's viral exanthems and herpesvirus branch, reported that funding earmarked by Congress for studies on CFS had been diverted to un related CDC projects. A subsequent congressional inquiry revealed that a total of $\$ 12.9$ million-as much as half of the funds appropriated for the CFS-had been redirected or improperly accounted for. Reeves has also filed a complaint with the US Office of Special Counsel alleging that his supervisor, Brian Mahy, reprimanded him, reduced his staff and downgraded his performance appraisals after Reeves reported the irregularities.

The GAO report describes a wide range of reforms implemented at the CDC to restore the diverted funds and improve accounting practices. Virginia Bales, deputy director for program manage ment at the $C D C$, explains that in the wake of the fund-shifting scandal, the agency has implemented "a comprehensive set of corrective actions that we think are going to lead to long-lasting improvements" in CDC bookkeeping. $M$ ahy has also been temporarily removed from his post as head of the division of viral and rickettsial diseases, but remains at the CDC.

CDC officials have said that the shift- ing of CFS funds was a result of the agency's need to respond quickly to public health emergencies that could not be predicted in the budget submitted to Congress. The CDC will be repaying the missing $\$ 12.9$ million to the CFS budget by reducing funding for other projects over the next three years.

In addition to CFS projects at the CDC, the GAO investigated how the NIH conducts its research activities on the condition and concluded: "While researchers and advocates have expressed concerns about the breadth of CFS research at CDC and $\mathrm{NIH}$, we found the agencies have conducted a broad range of activities related to CFS."

However, the GAO was critical of the CFSCoordinating Committee (CFSCC), a body chartered in 1996 to coordinate $\mathrm{NIH}$ and CDC research efforts. The report, which is available online (http://www.gao.gov), concludes that "while the [CFSCC] has been useful in keeping both federal agencies and the public informed of current developments at the agencies...it has yet to stimulate much discussion about how CDC and
NIH could coordinate their programs." The CFSCC was scheduled to meet last month to discuss the report's findings.

"To me this report is a total whitewash," says Jill McLaughlin, executive director of the National Chronic Fatigue Immune Dysfunction Syndrome (CFIDS) Foundation, a patient advocacy group, adding, "we have enough evidence that the coordinating committee has been completely ineffective. They've accomplished nothing-it's a gabfest."

The National CFIDS Foundation was formed by activists disillusioned with the CFIDS Association of America, the patient advocacy group that is represented on the CFSCC. According to M CLaughlin, both the NIH and CDC have shortchanged CFS research because of a bias against studying the disease, which some researchers have suggested is psychosomatic.

If there is such a bias at the NIH, it is not evident in Donna Dean, senior advisor to the acting director, who coordinates NIH research on CFS and co-chairs the CFSCC. "CFS is not all in your head," says Dean, adding, "It's well past the time to discard this trite and dismissive perspective." But the GAO report points out that some avenues of CFS research have remained unexplored because of a lack of grant proposals, suggesting that at least a few researchers may feel otherwise.

"We have not been able to encourage the leading investigators in these areas to submit grant applications. I don't know whether that is because [they] don't wish to study the illness or whether they haven't thought about it," says Dean.

\section{Alan Dove, Philadelphia}

\section{Wellcome extension to UK science museum}

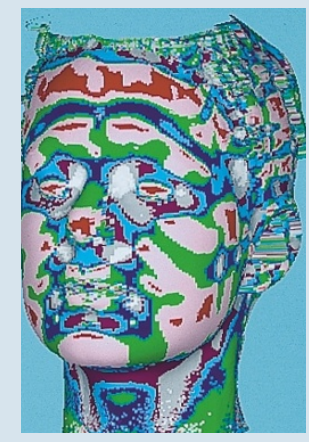

The Wellcome Trust has sponsored construction of a major new wing at the UK's Science Museum in London, which presents innovative and contemporary biomedical science to the public. The wing was opened last month in a ceremony attended by the Queen.

The $₫ 50$ million (US\$75 million) project includes a floor dedicated to the latest developments in research and exhibits, including sequencing equipment from the Human Genome Project, cloned mice and a piece of Dolly's fleece. Visitors can also take part in an ongoing research project -currently, a project mapping the genetics of facial features. Visitors can volunteer to have their faces scanned and a DNA sample taken. The Museum is encouraging leading academic centers to use the wing as a base for demonstrations of live research.

Natasha Loder, London 